n.tronos

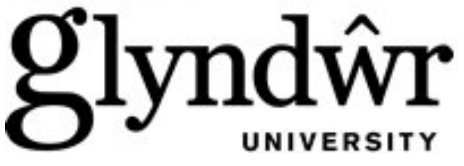

Glyndŵr University

Glyndŵr University Research Online

$1-1-2005$

\title{
Investigations of polarization purity and specific absorption rate for two dual-band antennas for satellite-mobile handsets
}

\author{
RA. Abd-Alhameed
}

M A. Mangoud

Peter S. Excell

Glyndwr University, p.excell@glyndwr.ac.uk

KKhalil

Follow this and additional works at: http://epubs.glyndwr.ac.uk/cair

Part of the Computer Engineering Commons, and the Computer Sciences Commons

\section{Recommended Citation}

Abd-Alhameed, R. A., Mangoud, M. A., Excell, P. S., \& Khalil, K. (2005) 'Investigations of polarization purity and specific absorption rate for two dual-band antennas for satellite-mobile handsets'. IEEE Transactions on Antennas and Propagation, 53(6), 2108-2110.

This Article is brought to you for free and open access by the Computer Science at Glyndŵr University Research Online. It has been accepted for inclusion in Computing by an authorized administrator of Glyndŵr University Research Online. For more information, please contact

d.jepson@glyndwr.ac.uk. 


\title{
Investigations of polarization purity and specific absorption rate for two dual-band antennas for satellite-mobile handsets
}

\begin{abstract}
A study of the effects of human proximity on the polarization purity of two types of circularly-polarized handset antennas for personal satellite communications was investigated using the hybrid method of moments (MoM)/finite-difference time-domain technique. Associated with this, assessments of specific absorption rate in the head were made. The method gave stable results, in accordance with physical expectations; good agreement with the pureMethod of Moments was shown in simplified cases omitting the head. The quadrifilar spiral antenna (QSA) was shown to be a propitious design for personal satellite communications.
\end{abstract}

\section{Keywords}

Circular polarization, finite-difference time-domain (FDTD), hybrid method, method of moments (MoM), satellite mobile

\author{
Disciplines \\ Computer Engineering | Computer Sciences
}

\section{Comments}

(C)2005 IEEE. Personal use of this material is permitted. However, permission to reprint/republish this material for advertising or promotional purposes or for creating new collective works for resale or redistribution to servers or lists, or to reuse any copyrighted component of this work in other works must be obtained from the IEEE. This material is presented to ensure timely dissemination of scholarly and technical work. Copyright and all rights therein are retained by authors or by other copyright holders. All persons copying this information are expected to adhere to the terms and constraints invoked by each author's copyright. In most cases, these works may not be reposted without the explicit permission of the copyright holder. This paper was published in IEEE Transactions on Antennas and Propagation in June 2005 sponsored by IEEE Antennas and Propagation Society. The definitive version is available at http://ieeexplore.ieee.org 


\section{Communications}

\author{
Investigations of Polarization Purity and Specific \\ Absorption Rate for Two Dual-Band Antennas for \\ Satellite-Mobile Handsets
}

Read A. Abd-Alhameed, M. Mangoud, P. S. Excell, and K. Khalil

\begin{abstract}
A study of the effects of human proximity on the polarization purity of two types of circularly-polarized handset antennas for personal satellite communications was investigated using the hybrid method of moments (MoM)/finite-difference time-domain technique. Associated with this, assessments of specific absorption rate in the head were made. The method gave stable results, in accordance with physical expectations; good agreement with the pure Method of Moments was shown in simplified cases omitting the head. The quadrifilar spiral antenna (QSA) was shown to be a propitious design for personal satellite communications.
\end{abstract}

Index Terms-Circular polarization, finite-difference time-domain (FDTD), hybrid method, method of moments (MoM), satellite mobile communications, specific absorption rate (SAR).

\section{INTRODUCTION}

Degradation of circular polarization purity (equivalent to degradation of axial ratio performance) of radiated fields from satellite-mobile handsets in the proximity of the human head has been addressed in the past [1]. Further, specific absorption rate (SAR) assessments in comparison with terrestrial mobile handset antennas have been presented in [2] and [3]. In [1] it was found that the presence of the head degraded the average axial ratio within a $50^{\circ}$ cone by between 2.9 and $9.1 \mathrm{~dB}$, which can have a significant effect on system performance. The antenna was rather larger than would be realistic, but the intention was to characterize the polarization issue only. Concerning the SAR in the user's head, in [2] and [3] the authors compared a quadrifilar helix antenna (QHA) with a monopole antenna. It was shown that, when operating in satellite mode, the QHA allowed input power to be increased by $27 \%$ for the same peak SAR level. Recently, novel satellite antenna designs have been proposed that use complex curved geometries to improve on the QHA [4]-[6].

It is concluded in [7] that the hybrid MoM/FDTD technique suits investigations of all of these types very well. In this paper, the polarization purity and SAR of two dual-band antennas for satellite-mobile handsets adjacent to the human head are investigated (see Fig. 1), using the hybrid computational method. These antennas are the quadrifilar spiral antenna (QSA) [8] and quadrifilar helical antenna (QHA) [6]. A small distance between the head and the handset was chosen to highlight the effects of the relatively high radiated power needed for satellite systems. The results for two operating frequency bands were studied: $1.61-1.6214 \mathrm{GHz}$ ( $L$-band) and $2.4835-2.5 \mathrm{GHz}$ ( $S$-band).

\section{Satellite Antennas on Handset Adjacent to REALISTIC HEAD MODEL}

The QSA and QHA are very attractive candidate antennas for satellite mobile handsets due to the symmetry of their geometry, properties of balanced feeding and their ability to provide circular polarization

Manuscript received December 13, 2002; revised October 10, 2004.

The authors are with the Mobile and Satellite Communication Research Centre, Bradford University, Bradford BD7 1DP, U.K. (e-mail: r.a.a.abd@ bradford.ac.uk).

Digital Object Identifier 10.1109/TAP.2005.848516

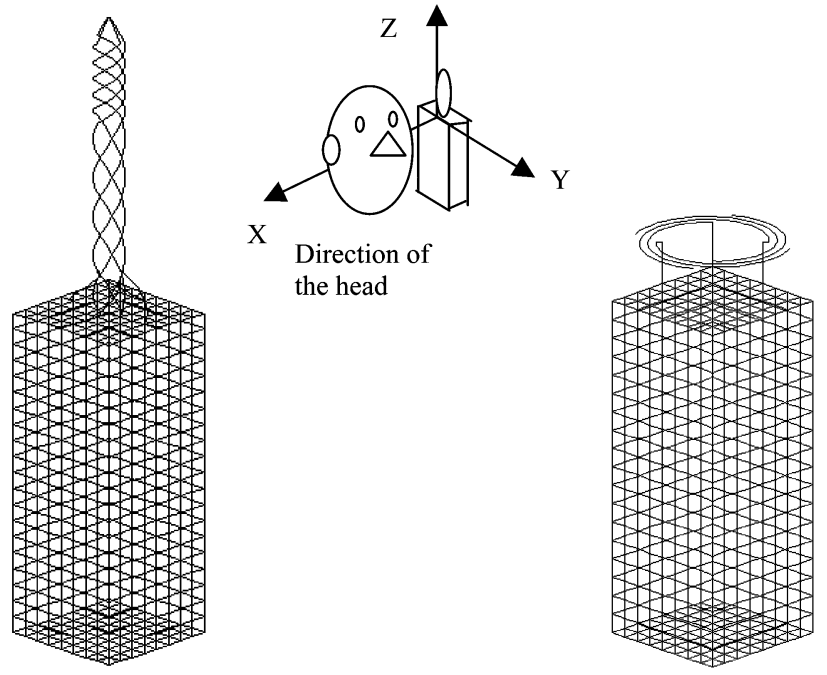

Fig. 1. Geometry for the dual band QHA (left) and QSA (right).

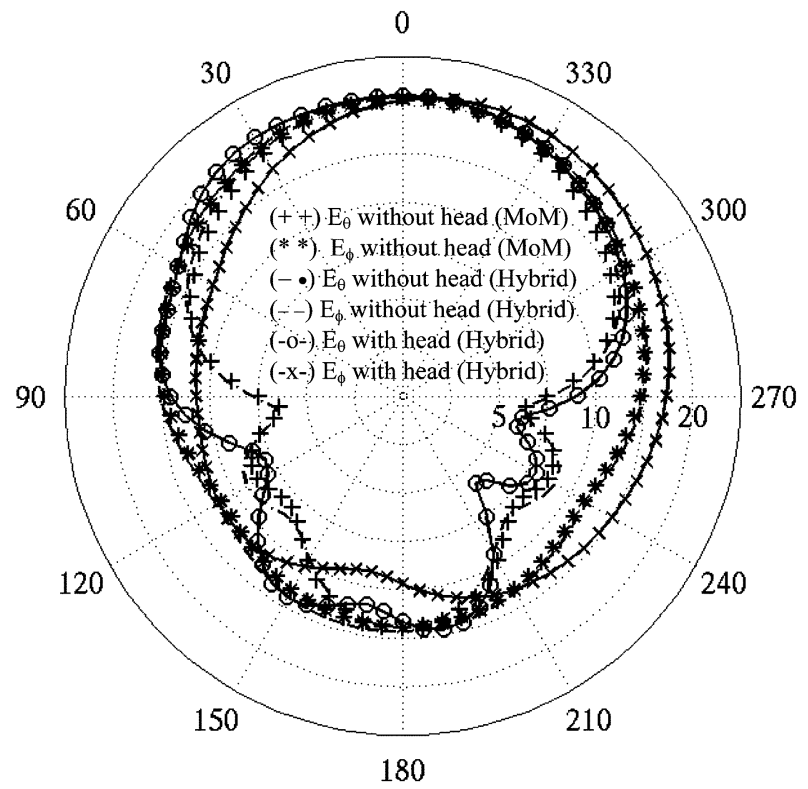

Fig. 2. $E_{\theta}$ and $E_{\phi}$ with and without the human head versus $\theta$ at $\phi=0^{\circ}$ for QSA ( $L$-band).

over a broad angular region. As seen in Fig. 1, the maximum dimension of the QSA is significantly smaller than that of the QHA, thus it is worthwhile to investigate both antenna performances in the vicinity of the human head, since the QHA is a well-established benchmark design against which the QSA can be compared, although the concentration of the near field distribution in their vicinities will be very different. The QSA consists of four spirals equally spaced circumferentially (placed at $90^{\circ}$ to each other) whereas the QHA has four helices placed at $90^{\circ}$ to each other. Both antennas are fed with equal amplitude signals with $90^{\circ}$ phase difference between feeding sources (i.e., $0^{\circ}, 90^{\circ}, 180^{\circ}$, and $270^{\circ}$ ). The handset dimensions were selected to be $56 \times 56 \times 140 \mathrm{~mm}$ : this is rather larger than modern handsets, but was a convenient choice for prototype studies, including future experimental tests. It should be noted that the QSA here is fed from its inner perimeter rather than the outer ends of the arms since this is more convenient. Problems can arise 


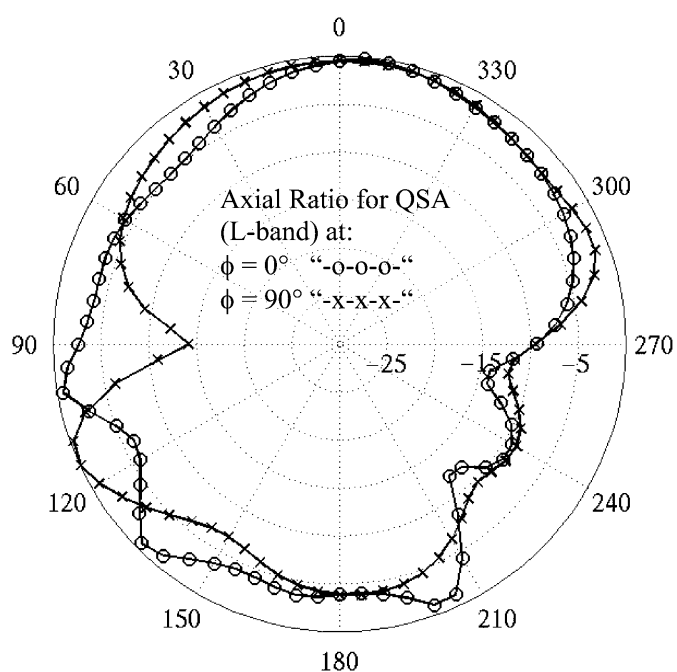

(a)

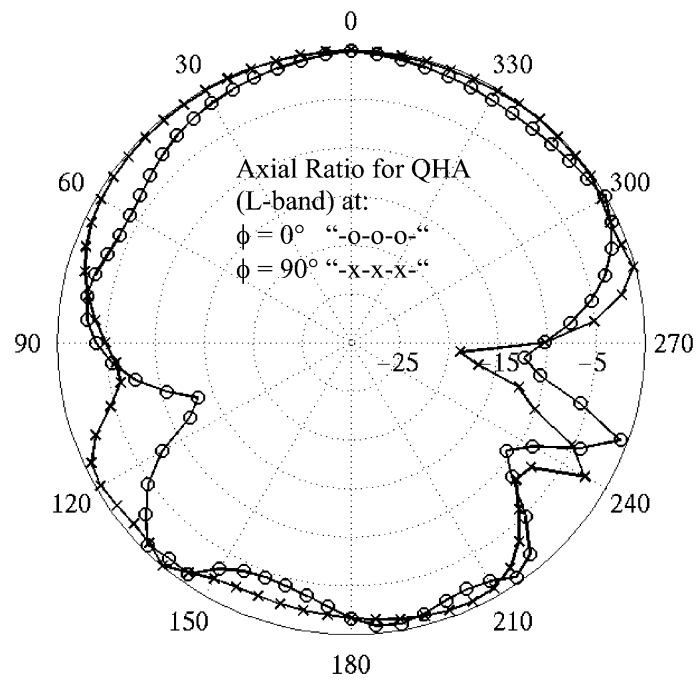

(c)

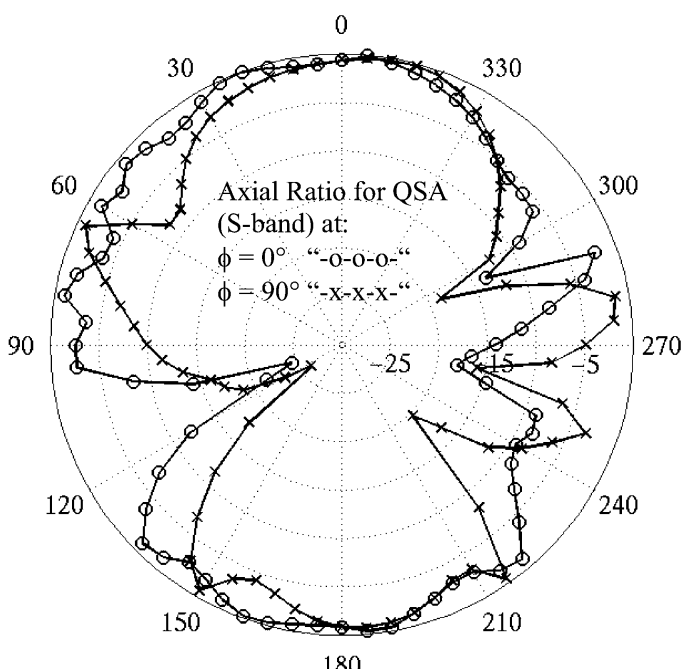

(b)

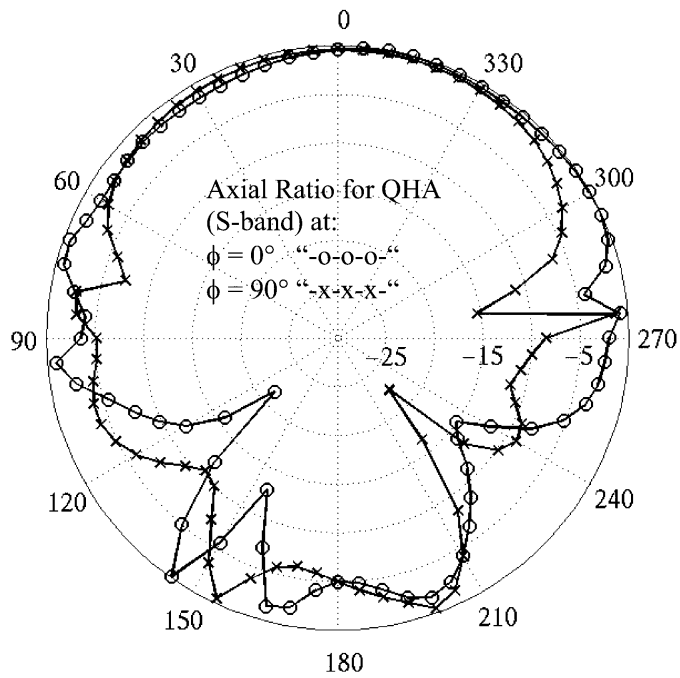

(d)

Fig. 3. Axial ratio in dB versus $\theta$ for two different $\phi$ angles; (a) QSA at $L$-band; (b) QSA at $S$-band; (c) QHA at $L$-band; (d) QHA at $S$-band.

with inner feeding when the distance between the feed lines is small, causing significant mutual coupling effects.

The size of the equivalent Huygens surface that surrounds the antenna and handset (the MoM region) inside the FDTD grid was selected to be $36 \times 36 \times 72$ FDTD cells for the QSA antenna and $36 \times 36 \times 117$ cells for the QHA antenna. This closed surface was placed adjacent to a realistic 3D head image. The FDTD details for both frequency bands were as follows: the FDTD cell size was 2.5 $\mathrm{mm}$; the sizes of the problem spaces were $127 \times 96 \times 127$ cells $(\mathrm{QSA})$ and $127 \times 91 \times 137$ cells $(\mathrm{QHA})$. The time steps at $L$-band and $S$-band were 3.375 ps and 2.75 ps respectively. The total number of cycles simulated for both operating frequencies was 25 . The tissue-classified head used in this work is given in [10]: it uses 16 different tissue dielectric properties. The handset body was placed $7.5 \mathrm{~mm}$ from the nearest point of the head tissue. These parameters are significantly more realistic than those used in the earlier pilot study [9], which used $5 \mathrm{~mm}$ cell size, handset dimensions $80 \times 80 \times 133.3 \mathrm{~mm}$ and a minimum separation distance from the head of $2 \mathrm{~cm}$, with a QHA only.

\section{NumERICAL Results With AND Without THE HEAD}

The relative bandwidth (for VSWR $\leq 3$ ) at the input ports of the antennas shown in Fig. 1, without the head present, are $5 \%$ at $L$-band and $8.2 \%$ at $S$-band (for the QSA), and $3 \%$ at $L$-band and $6.5 \%$ at $S$-band (for the QHA). Good axial ratios for both antennas in the two bands were observed with the following power gains: $5 \mathrm{~dB}$ ( $L$-band) and $6.5 \mathrm{~dB}$ ( $S$-band) for the QSA; $6 \mathrm{~dB}$ ( $L$-band) and $8 \mathrm{~dB}$ ( $S$-band) for the QHA. Reasonable circular polarization elevation angle coverages of approximately $\pm 50^{\circ}$ (QSA) and $\pm 45^{\circ}$ (QHA) were obtained, these angles being similar for both the L- and S-bands. The field patterns (for $1 \mathrm{~W}$ input power to lossless antennas) with and without the head for the QSA antenna at $1.6 \mathrm{GHz}$ are shown in Fig. 2. As shown, the field patterns, without the head, obtained using the hybrid method [7] and the pure Method of Moments (MoM) were in good agreement: the worst-case disagreement is about $0.5 \mathrm{~dB}$ (relative to $8 \mathrm{~dB}$, at $120^{\circ}$ in the $E_{\theta}$ curves), corresponding to $5.6 \%$ variation in the field strength. This only occurs in a relatively weak-field zone which is more susceptible to numerical noise: the majority of the curves are in much better agreement. It is considered that this adequately verifies the validity of the hybrid method. When the head is added to the model, the field patterns obtained show that, over the useful range of elevation angles, the fields are not greatly changed, but the $E_{\phi}$ component in directions close to the head is attenuated by around $5 \mathrm{~dB}$, which will cause some deterioration of the axial ratio.

The axial ratio results were computed for the $x$ - $z$ plane $\left(\phi=0^{\circ}\right)$ and $y-z$ plane $\left(\phi=90^{\circ}\right)$ in the presence of the head. Fig. 3(a) and (b) 
TABLE I

COMPUTED SAR AND POWER ABSORBED FOR BOTH QSA AND QHA ANTENNAS

\begin{tabular}{c|c|c|c|c|c}
\hline $\begin{array}{c}\text { Distance } \\
(\mathrm{mm})\end{array}$ & Computed parameters & \multicolumn{2}{|c|}{ QSA } & \multicolumn{2}{c}{ QHA } \\
\cline { 3 - 6 } & & $1.6 \mathrm{GHz}$ & $2.5 \mathrm{GHz}$ & $1.6 \mathrm{GHz}$ & $2.5 \mathrm{GHz}$ \\
\hline 7.5 & SAR unaveraged $(\mathrm{W} / \mathrm{kg})$ & 6.759 & 17.312 & 2.003 & 0.9 \\
& SAR averaged over $1 \mathrm{~g}(\mathrm{~W} / \mathrm{kg})$ & 1.399 & 1.088 & 0.503 & 0.267 \\
& SAR averaged over $10 \mathrm{~g}(\mathrm{~W} / \mathrm{kg})$ & 0.138 & 0.836 & 0.465 & 0.227 \\
& Power absorbed & 174 & 130 & 85.6 & 44.3 \\
& $\mathrm{P}_{\mathrm{rad}} / \mathrm{P}_{\mathrm{abs}}$ & 4.75 & 6.688 & 10.68 & 21.57 \\
\hline \multirow{2}{*}{15} & SAR unaveraged $(\mathrm{W} / \mathrm{kg})$ & 2.871 & 11.6933 & 1.074 & 0.4452 \\
& SAR averaged over $1 \mathrm{~g}(\mathrm{~W} / \mathrm{kg})$ & 0.644 & 0.7765 & 0.271 & 0.1047 \\
& SAR averaged over $10 \mathrm{~g}(\mathrm{~W} / \mathrm{kg})$ & 0.614 & 0.5682 & 0.252 & 0.0935 \\
& Power absorbed & 113.4 & 84.5 & 59.3 & 17.7 \\
& $\mathrm{P}_{\mathrm{rad}} / \mathrm{P}_{\mathrm{abs}}$ & 7.816 & 10.8357 & 15.87 & 55.505 \\
& & & & & \\
\hline
\end{tabular}

present these ratios for the QSA at $L$-band and $S$-band respectively, and Fig. 3(c) and (d) show it for the QHA at $L$-band and $S$-band respectively. The distance between the handset and the head was kept at $7.5 \mathrm{~mm}$ for all cases. Reasonably good circular polarization coverage is observed over the elevation angle range of $\pm 40^{\circ}$ for both bands of interest. The circular polarization purity for both bands decreases in the presence of the head by 2 to $5 \mathrm{~dB}$, which is much better than for the single axial mode helix [1].

The calculated peak SAR in the head, the maximum averaged SAR over masses of $10 \mathrm{~g}$ and $1 \mathrm{~g}$ and the power absorbed for different distances between the head and the handset for both antennas shown in Fig. 1 are summarized in Table I for an input power of $1 \mathrm{~W}$. The computations indicate that approximately $24 \%$ ( $L$-band) and $14 \%$ ( $S$-band) of the total delivered power was absorbed by the head when using the QSA, while $13 \%$ ( $L$-band) and $8 \%$ ( $S$-band) of the total delivered power was absorbed by the head when using the QHA. These results are much lower than those reported in [7] for a GSM 1800 terrestrial handset, for which peak SAR in the head was between 10 and $21 \mathrm{~W} / \mathrm{kg} / \mathrm{W}$ for a head-handset separation of $7.5 \mathrm{~mm}$. Additionally, the head absorbed between 48 and $68 \%$ of the power delivered to the antenna. The decrease in the absorption levels for satellite terminals is partly due to the direction of radiation being different for the two cases and partly to the inherently somewhat greater distance between the head and the antenna.

\section{CONCLUSION}

The effect of the presence of a head model on the axial ratio and the circular polarization radiation purity for two dual-band satellite-mobile handset antennas was investigated in detail using a hybrid MoM/FDTD technique. The computations indicated that approximately $14 \%$ to $24 \%$ of the total delivered power was absorbed by the head for the QSA antenna and $8 \%$ to $17 \%$ for the QHA antenna, compared with 48 to $68 \%$ for a canonical GSM terrestrial handset. The results also show the impact of the presence of the head on the circular polarization purity of the satellite antennas, indicated by the axial ratio: for both bands, this varied between 2 and $5 \mathrm{~dB}$ over the required elevation angle range, which is acceptable, given the presence of the head. Because of its small size and acceptable performance, the QSA has been shown to be a propitious design for personal satellite communications.

The nature of satellite-mobile services demands somewhat higher radiated powers and power gains than with terrestrial systems, leading to public concerns about the levels of SAR in the head. These results show that such concerns are groundless, at least in comparison with terrestrial systems: they also demonstrate the power and utility of the hybrid field computation method for such complex geometries in the presence of human tissue or other lossy dielectrics.

\section{REFERENCES}

[1] J. S. Colburn and Y. Rahmat-Samii, "Human proximity effects on circular polarized handset antennas in personal satellite communications," IEEE Trans. Antennas Propag., vol. 46, no. 6, pp. 813-820, Jun. 1998.

[2] P. Suvannapattana and S. R. Saunders, "Satellite and terrestrial mobile handheld antenna interactions with the human head," Proc. Inst. Elect. Eng. Microwaves Antennas and Propagation, vol. 146, no. 5, pp. 305-310, 1999.

[3] A. A. Agius, S. M. Leach, P. Suvannapattana, and A. R. Saunders, "Effects of the human head on the radiation pattern performance of the quadrifilar helix antenna," in Proc. IEEE Int. Symp. Antennas Propagation, vol. 2, 1999, pp. 1114-1117.

[4] J. S. Colburn and Y. Rahmat Samii, "Quadrifilar-curl antenna for the "Big-LEO" mobile satellite service system," in IEEE Int. Symp. Antennas Propag., vol. 2, 1996, pp. 1088-1091.

[5] M. E. Ermutlu, "Modified quadrifilar helix antennas for mobile satellite communication," in Proc. IEEE Conf. Antennas and Propagation for Wireless Communications, 1998, pp. 141-144.

[6] S. M. Daddish, R. A. Abd-Alhameed, and P. S. Excell, "New designs for dual band antennas for satellite-mobile communications handsets," Appl. Comput. Electromagn. Soc. J., vol. 15, no. 3, pp. 248-258, 2000.

[7] M. A. Mangoud, R. A. Abd-Alhameed, and P. S. Excell, "Simulation of human interaction with mobile telephones using hybrid techniques over coupled domains," IEEE Trans. Microw. Theory Tech., vol. 48, no. 11, pp. 2014-2021, 2000.

[8] K. Alazhari, R. A. Abd-Alhameed, P. S. Excell, and K. Khalil, "New design for single and dual band quadrifilar spiral antennas (QSA) for satellite-mobile handsets," in Proc. Inst. Elect. Eng. Int. Conf. Antennas and Propagation, vol. 2, Apr. 2001, pp. 750-753.

[9] M. A. Mangoud, R. A. Abd-Alhameed, and P. S. Excell, "Investigation of polarization purity and SAR for personal satellite communications antennas using a hybrid computational method," Electron. Lett., vol. 37, no. 21, pp. $1272-1274$, Oct. 2001.

[10] P. S. Excell, "Computer modeling of high frequency electromagnetic field penetration into the human head," Meas. Contr., vol. 31, no. 6, pp. 170-175, 1998. 